\title{
Reciprocal influence of arsenic and iron on the long-term immobilization of arsenic in contaminated soils
}

\author{
I. Carabante ${ }^{1,2}$, J. Antelo ${ }^{3}$, J. Lezama-Pacheco ${ }^{2}$, S. Fiol ${ }^{3}$, S. Fendorf ${ }^{2} \&$ J. Kumpiene ${ }^{1}$ \\ ${ }^{1}$ Waste Science and Technology, Luleå University of Technology, Luleå, Sweden \\ ${ }^{2}$ Department of Earth System Science, Stanford University, Stanford, CA, USA \\ ${ }^{3}$ Technological Research Institute, University of Santiago de Compostela, Santiago de Compostela, Spain
}

\begin{abstract}
The main aim of this work was to evaluate the fate of arsenic associated with iron minerals in contaminated soils. The ageing behavior of synthetic arsenic-bearing poorly crystalline minerals - ferrihydrite and schwertmannite - was studied. Arsenic showed a passivation effect on poorly crystalline minerals, delaying their transformation towards more crystalline iron oxides. These results agreed well with studies performed on contaminated soils and sediments. These results are relevant in order to understand the long-term mobility of arsenic in contaminated soils and sediments. Iron oxides sequesters arsenic efficiently and, reciprocally, arsenic stabilize the mineral, delaying its transformation towards more crystalline phases.
\end{abstract}

\section{INTRODUCTION}

The main aim of this work was to evaluate the fate of arsenic (As) associated with iron (Fe) minerals in contaminated soils. In particular two different systems were studied: i) remediation of arsenic contaminated soils by addition of zero-valent iron (ZVI) and ii) immobilization of arsenic by secondary iron precipitates on acid mine drainage (AMD) systems.

A cost-effective method to reduce the risk, i.e. mobility and bioavailability, of As in a contaminated site is to apply in situ stabilization techniques, keeping the soil on site. This technology is based on changing the As geochemistry of the soil by adding a chemical amendment which promotes As immobilization by for example precipitation or adsorption. Addition of ZVI to the soil, which will immobilize arsenate after ZVI oxidation, is usually proposed as an effective in-situ remedation technique reducing As leaching up to $98 \%$ (Kumpiene et al., 2008; 2006; Mench et al., 2002). The applicability of these techniques is becoming possible as more European countries are accepting a risk-based approach when defining whether the site is contaminated or not. In this approach the main risk-defining factor of a site is the contaminant bioavailability and mobility and not on its total concentration in the soil. Although the promising results obtained using this technique, questions regarding the long-term stability of the immobilized contaminant in the soil must be answered before establishing in-situ chemical stabilization as a widely accepted technique. The particle size of the $\mathrm{Fe}$ oxide particles in the soil will ultimately define the arsenate adsorption (immobilization), e.g. the smaller the $\mathrm{Fe}$ oxide particles are the higher the arsenate adsorption capacity of the Fe oxide (Waychunas et al., 2005). Since very small Fe oxide nanoparticles are formed upon the oxidation product of metallic ZVI, the immobilization of As in soils by $\mathrm{Fe}$ amendments can reach a high efficiency. The oxidation products of ZVI would be at first small $\mathrm{Fe}$ oxy-hydroxides such as ferrihydrite or lepidocrocite $(\gamma-\mathrm{FeOOH})$ (Cornell \& Schwertmann, 1996). The ageing of these nanoparticles in the soil might induce crystal growth and/or phase transformation, which would plausibly decrease the effectiveness of the remediation method with time.

Oxidation of iron sulfide minerals present in mining areas lead to AMD. AMD causes acidification of surface waters in combination with the release of trace elements (TE), such as As, Cr, U, Mo, Zn and $\mathrm{Cu}$. AMD has been identified as the main cause of surface water contamination on the mid-Atlantic region of the USA (U.S. EPA, 2018). Worldwide, about $20,000 \mathrm{~km}$ of water streams and about 72,000 ha of surface waters were estimated to be seriously damaged as a consequence of AMD (Johnson \& Hallberg, 2005).

Iron secondary minerals initially sequester large amounts of trace elements (TE), such as arsenic. However, the long-term immobilization of TE in these mineral phases will be defined by the stability of these minerals. Schwertmannite is a metastable mineral, transforming eventually into more stable phases such as hematite and goethite (Bigham \& Nordstrom, 2000). Jarosite is stable under acidic conditions while it dissolves at natural $\mathrm{pH}$ (Smith et al., 2006). Interestingly, certain cations have been observed to increase the stability of secondary minerals related to AMD. 
For instance, the presence of $\mathrm{Cu}$ significantly enhances the stability of schwertmannite (Antelo et al., 2013) and some results show evidences pointing towards arsenate stabilizing schwertmannite (Regenspurg \& Peiffer, 2005). Yet, the number of studies assessing the effect of TE on the stability and reactivity of iron oxyhydroxysulfates is limited. Summarizing, the bonding mechanism of sequestration and the effect of TE on the reactivity and stability of iron oxyhydroxysulfates are understudied and can be considered key knowledge to better understand the mobility of TE in AMD systems.

\section{METHODS/EXPERIMENTAL}

\subsection{Ageing experiments}

As-bearing ferrihydrite: Synthetic ferrihydrite was used for this experiment. Three different As loadings were studied, arsenic to iron molar ratio of 0 , 0.01 and 0.1 . The transformation of ferrihydrite into hematite was studied by means of differential scanning calorimetry (DSC). Dried-powder samples of the three materials were heated up in the DSC furnace from room temperature up to $800^{\circ} \mathrm{C}$ at a heating rate of $10^{\circ} \mathrm{C} \mathrm{min}^{-1}$ under a synthetic air atmosphere. In order to better understand the processes taking place along the transformation curves, samples were heated up to different temperatures in a muffle oven at the same heating rate than in the DSC analysis, $10^{\circ} \mathrm{C} \mathrm{min}^{-1}$. This different samples were spare for As K-edge EXAFS, Fe K-edge EXAFS, sequential extraction and FTIR measurements.

ZVI amended soils: Different sites in Europe that had been previously in-situ treated by addition of $2 \%$ ZVI were selected in this study. The time from which the soils were treated changed from 2 to 15 years for the different sites. We had access to both soil that had been treated with ZVI but also control samples to which ZVI was not added. The iron mineralogy of the different soils was extensively evaluated by means of Fe-K edge EXAFS as well as sequential extraction.

As-bearing AMD systems: the adsorption of arsenic on synthetic ferrihydrite was characterized by batch adsorption experiments as a function of $\mathrm{pH}$, from $\mathrm{pH}$ 3 to 9 and from an arsenic to iron molar ratio from 0 to 0.7. Subsequently schwertmannite bearing arsenic to iron molar ratio of 0.1 and 0 was aged in an electrolyte background suspension at $\mathrm{pH} \mathrm{3,5}$ and 7. The Portapego stream at Mina Touro, Spain, shows evidences of acid mine drainage. Sediments from this stream was collected. The iron mineralogy of the sediments were mostly schwertmannite. The same aging experiments, at $\mathrm{pH} 3$, were carried out with these sediments.

\subsection{X-ray absorption spectroscopy}

Fe K-edge XAS and As K-edge XAS spectra were collected, at ambient temperature and pressure, on beam line 7.3, 4.3 and 11.2 at the Stanford Synchrotron Radiation Lightsource at SLAC National Laboratory
Accelerator, beam line I811 at Max Lab Synchrotron facility in Sweden, beam line 22 CLAESS at ALBA Synchrotron light facility and at beam line BM25 at ERSF. Fe K-edge data of soil samples were measured on fluorescence mode using a PIPPS detector whereas synthetic iron oxides were measured on transmission mode using ionization chambers as I0 and I1. The data was self-calibrated with a Fe foil placed between I1 and I2. As K-edge spectra were obtained on fluorescence mode using a solid state multiple germanium elements detector.

\section{RESULTS AND DISCUSSION}

\subsection{As-bearing ferrihydrite}

The DSC curve of pristine ferrihydrite showed a sharp transformation event at $435^{\circ} \mathrm{C}$. This event corresponds to the transformation of ferrihydrite into hematite. The DSC curves of the As-bearing ferrihydrite showed a more complex transformation pattern. More importantly, the transformation events were delayed: at $490^{\circ} \mathrm{C}$ for an arsenic to iron molar ratio of 0.01 and at $647^{\circ} \mathrm{C}$ for an $\mathrm{As} / \mathrm{Fe}$ molar ratio of 0.1 . The transformation processes assumed by the DCS curves were confirmed by Fe-EXAFS. The adsorption of arsenic thus delayed the thermal transformation of ferrihydrite.

Arsenic fractionation changed upon the thermal transformation of ferrihydrite. A higher fraction of arsenic was associated with the ferrihydrite fraction instead of with the hematite fraction. Interestingly, only $5 \%$ of arsenic became labile in the exchangeable fractions. Although this is a low percentage, this could explain fast arsenic leaching from soils after thermal treatment. The arsenic atomic environment changed also upon the thermal transformation of iron as shown by As K-edge EXAFS.

\subsection{ZVI amended soils}

The iron mineralogy of all the sites analyzed in this studied had strong dependence on the initial mineralogy of the site and conditions such as humidity, temperature and organic content. Our results indicated that the fraction of amorphous iron oxides, i.e. the most reactive fraction regarding the immobilization of arsenic, increased upon addition of ZVI. This trend was observed in all sites independently on the time after which the amendment was applied to the soils, 2 years, 6 years, 8 years, 12 years and 15 years. These results showed that the immobilization of arsenic and other TE was still a success after almost a few decades from the addition of ZVI.

\subsection{AMD systems}

The transformation of synthetic schwertmannite as well as schwertmannite sediments from Mina Touro 
had a strong dependence on the presence of arsenic in the system during the 300 days in which the transformation was monitored. Higher transformation rate were observed in the absence of arsenic. In particular schwertmannite did not transformed into goethite, or if it did it was to a minor extend, at $\mathrm{pH} 3$ at an arsenic to iron molar ratio of 0.1 . The transformation of schwertmannite was also $\mathrm{pH}$ dependent, obtaining higher degree of transformations at higher $\mathrm{pH}$ values.

\section{CONCLUSIONS}

One of the main concerns regarding the long-term immobilization of arsenic is that the main iron oxides involved in such immobilization are metastable. This study shows that a metastable iron oxide such as ferrihydrite delays its transformation towards more crystalline phases in the presence of arsenic. Interestingly, the immobilization of arsenic contaminated soils by addition of ZVI was a success for about two decades. These results are relevant in order to understand the long-term mobility of arsenic in ZVI-amended soils and from AMD systems. Iron oxides sequesters arsenic efficiently and, reciprocally, arsenic stabilize the mineral, delaying its transformation towards more crystalline phases.

\section{ACKNOWLEDGEMENTS}

The Wallenberg Foundation and $\AA$ Forsk Foundation are acknowledged for financial support. SSRL, ALBA, Max-Lab and ESRF are acknowledged for granting our beam time proposals under which X-Ray absorption measurements presented in this work were performed.

\section{REFERENCES}

Antelo, J., Fiol, S., Gondar, D., Pérez, C., López, R. \& Arce, F. 2013. $\mathrm{Cu}$ (II) incorporation to schwertmannite: effect on stability and reactivity under AMD conditions. Geochim. Cosmochim. Acta 119: 149-163.

Bigham \& Nordstrom. 2000. Iron and aluminum hydroxysulfates from acid sulfate waters. Rev. Mineral. Geochem. 40(1): 351-403.

Cornell, R.M. \& Schwertmann, U. 2004. The Iron Oxides: Structure, Properties, Reactions, Occurrences and Uses. Wiley \& Sons.

Johnson, D.B. \& Hallberg, K.B. 2005. Acid mine drainage remediation options: a review. Sci. Total Environ. 338(1-2): 3-14.

Kumpiene, J., Lagerkvist, A. \& Maurice, C. 2008. Stabilization of $\mathrm{As}, \mathrm{Cr}, \mathrm{Cu}, \mathrm{Pb}$ and $\mathrm{Zn}$ in soils using amendments a review. Waste Manag. 28(1): 215-225.

Kumpiene, J., Ore, S., Renella, G., Mench, M., Lagerkvist, A. \& Maurice, C. 2006. Assessment of zerovalent iron for stabilization of chromium, copper and arsenic in soil. Environ. Pollut. 144(1): 62-69.

Mench, M., Vangronsveld, J., Clijsters, H., Lepp, N.W. \& Edwards, R. 2000. In situ immobilization and phytostabilization of contaminated soils. In: N. Terry, G. Bañuelos (eds) Phytoremediation of Contaminated Soils and Waters. CRC Press, Boca Raton, FL, pp. 323-358.

Regenspurg, S. \& Peiffer, S. 2005. Arsenate and chromate incorporation in schwertmannite. Appl. Geochem. 20(6): 1226-1239.

Smith, A.M.L., Hudson-Edwards, K.A., Dubbin, W.E. \& Wright, K. 2006. Dissolution of jarosite $\left[\mathrm{KFe}_{3}\left(\mathrm{SO}_{4}\right)_{2}\right.$ $(\mathrm{OH})_{2}$ ] at $\mathrm{pH} 2$ and 8: insights from batch experiments and computational modelling. Geochim. Cosmochim. Acta 70(3): 608-621.

U.S. Environmental Protection Agency (2018) www. sosbluewaters.org/epa-what-is-acid-mine-drainage $\% 5 \mathrm{~B} 1$ \%5D.pdf. (Accessed on April 3, 2018).

Waychunas, G.A., Kim, C.S. \& Banfield, J.F. 2005. Nanoparticulate iron oxide minerals in soil and sediments: unique properties and contaminant scavenging mechanisms. J. Nanopart. Res. 7(4-5): 409-433. 